\title{
PRODUÇÃO DE HIDROGÊNIO POR MEIO DA CORROSÃO ELETROQUÍMICA ACELERADA USANDO $\mathrm{H}_{2} \mathrm{SiF}_{6} \mathrm{E} \mathrm{HCl}$
}

\author{
T. C. MAEDA ${ }^{1}$, L. T. SILVA ${ }^{1}$, L. C. CAIXETA ${ }^{1}$, R. A. ANTONELLI ${ }^{1}$, A. C. GRANATO ${ }^{1}$, \\ D. M. FERNANDES ${ }^{1}$, S. C. DANTAS ${ }^{1}$, e G. R. P. MALPASS ${ }^{1}$ \\ ${ }^{1}$ Universidade Federal do Triângulo Mineiro, Departamento de Engenharia Química \\ E-mail para contato: tatianemaeda@hotmail.com
}

RESUMO - Introdução: Atualmente, há um elevado consumo dos recursos naturais, maior demanda energética e acúmulo de resíduos industriais. Dessa forma, são necessárias tecnologias que visem a produção de energia suficiente para esse consumo, sem intensificar os danos ambientais. $\mathrm{O}$ hidrogênio destaca-se por seu elevado potencial energético e um dos métodos de obtenção é a corrosão ácida. Objetivos: Produzir $\mathrm{H}_{2}$ utilizando $\mathrm{H}_{2} \mathrm{SiF}_{6}$ (resíduo da indústria de fertilizantes), metais residuais como fonte de ferro em conjunto com $\mathrm{HCl}$ na tentativa de facilitar a corrosão. Metodologia: os reagentes utilizados foram vergalhão (resíduo de construções), pó de ferro ( resíduo de serralherias/ tornearias) e palha de aço, $\mathrm{H}_{2} \mathrm{SiF}_{6}, \mathrm{HCl}$ e água. Foi montado um sistema que consiste em um erlenmeyer, ligado por uma mangueira até o interior de uma proveta preenchida com água, imersa dentro de um béquer com água. No interior do erlenmeyer, foram colocadas massas distintas do metal e variadas soluções com $\mathrm{H}_{2} \mathrm{SiF}_{6}$ e $\mathrm{HCl}$. À medida que a reação ocorria, o gás ocupava o espaço da água na proveta e assim obteve-se medidas de volumes do gás. Resultados: De uma forma geral foi possível verificar que o aumento de todas as variáveis consideradas apresentou uma influência positiva na resposta. Foi feita análise do gás por cromatografia gasosa e havia apenas gás hidrogênio e ar. Conclusão: Este é um método eficiente e não é caro, o qual não emite gás tóxico/poluente, sendo gerador de uma nova fonte de energia sustentável.

\section{INTRODUÇÃO}

Atualmente, há um elevado consumo dos recursos naturais, e com isso uma maior demanda energética e acúmulo de resíduos industriais no meio ambiente. Dessa forma, é importante, buscar-se tecnologias que visem a produção de energia que seja suficiente para esse consumo, sem intensificar os danos ambientais. Comercialmente importante, o hidrogênio destaca-se por seu elevado potencial energético, sendo um combustível de alta eficiência e baixo poluente. Segundo Lee (1999), apesar de ser o elemento mais abundante do universo, o hidrogênio apresenta pequena quantidade na atmosfera, pois o campo gravitacional terrestre é muito pequeno para retê-lo, uma vez que é muito leve.

Alguns métodos de obtenção de $\mathrm{H}_{2}$ utilizados são a reforma a vapor e a eletrólise. Porém, na reforma a vapor é utilizado o metano, o qual é um combustível fóssil e o processo resulta a emissão de gases que contribuem para o efeito estufa. Já a eletrólise, necessita de corrente elétrica através da água para que haja separação dos elementos, hidrogênio e oxigênio, o que torna o processo caro. Por isso, um método viável é a obtenção de $\mathrm{H}_{2}$ pela corrosão ácida, uma vez que não emite gases poluentes e o processo não é caro. Segundo Gentil (2014), a corrosão ácida consiste na redução do íon $\mathrm{H}^{+}$gerando $\mathrm{H}_{2}$, como mostra a 
Equação 1. Trata-se de um processo espontâneo e como qualquer processo eletroquímico, para manter um equilíbrio de cargas, duas reações ocorrem na superfície: a reação dissolução do metal (corrosão), ou reação anódica e a reação catódica. As reações envolvidas são mostradas nas Equações 2, 3 e 4.

$$
2 H^{+}+2 e^{-} \rightarrow \mathrm{H}_{2}
$$

Ânodo $\mathrm{Fe} \rightarrow \mathrm{Fe}^{2+}+2 \mathrm{e}^{-}$

$$
\text { Cátodo } 2 \mathrm{H}^{+}+2 e^{-} \rightarrow \mathrm{H}_{2}
$$

Geral $2 \mathrm{H}^{+}+\mathrm{Fe} \rightarrow \mathrm{H}_{2}+\mathrm{Fe}^{2+}$

Uma breve análise da literatura mostra que estudos da geração de $\mathrm{H}_{2}$ por corrosão não são muitos comuns. Análises semelhantes foram realizadas por (YU; UAN; HSU, 2012), em que um grande volume de $\mathrm{H}_{2}$ foi obtido a partir sucata de $\mathrm{Mg}$ de baixa qualidade, simplesmente ao ser mergulhado em solução de ácido cítrico contendo água do mar, provando que a corrosão eletroquímica é um método eficaz na geração de $\mathrm{H}_{2}$. A maioria dos estudos deste tipo usam metais como Al (LIANG et al., 2016) ou Mg (YU; UAN; HSU, 2012), devido à termodinâmica favorável do processo. Porém, as pesquisas sobre produção de $\mathrm{H}_{2}$ usando Fe muitas vezes são limitadas ao simples estudo de corrosão e sua prevenção, e não para a produção de $\mathrm{H}_{2}$ em si.

Nesse processo de oxirredução, um dos ácidos que pode ser utilizado é o ácido hexafluossilício $\left(\mathrm{H}_{2} \mathrm{SiF}_{6}\right)$. Na produção de fertilizantes fosfatados a rocha fosfática é digerida pelo ácido súlfurico. Em seguida, ocorre a reação do HF com o óxido de silício. Essa reação é exotérmica e libera um gás nocivo, o tetrafluoreto de silício $\left(\mathrm{SiF}_{4}\right)$. É feita a lavagem desse gás e com isso obtém-se o $\mathrm{H}_{2} \mathrm{SiF}_{6}$. Existem algumas utilizações para esse ácido, como fluoretação da água, tratamento de limpeza de superfícies metálicas e controle de $\mathrm{pH}$ de indústrias têxteis e lavanderias. Porém, há uma produção muito grande desse ácido sendo necessárias novas aplicações.

Portanto, dada necessidade de novas fontes de energia, evitando-se o acúmulo de rejeitos na natureza e devido à importância industrial e energética do gás hidrogênio, objetivase o uso de $\mathrm{H}_{2} \mathrm{SiF}_{6}$ e de metais residuais como fonte de ferro em conjunto $\mathrm{HCl}$ na tentativa de facilitar o processo de corrosão e acelerar a produção de $\mathrm{H}_{2}$.

\section{METODOLOGIA}

Os materiais utilizados foram vergalhão (resíduo de construções), pó de ferro ( resíduo de serralherias/ tornearias) e palha de aço como fonte de ferro, erlenmeyer de $50 \mathrm{~mL}$, proveta de $250 \mathrm{~mL}$, béquer de $1 \mathrm{~L}$, rolha, mangueira, balança analítica, e cronômetro.

Preparou-se a solução de $\mathrm{HCl} 1$ molar, através de diluição da solução da previamente comprada (12 molar). Pesou-se a massa de metal desejada utilizando um béquer e uma balança analítica. Foi montando um sistema, como mostrado na Figura 1. No erlenmeyer 
foram introduzidos o metal e a solução de $\mathrm{H}_{2} \mathrm{SiF}_{6}$ com $\mathrm{HCl}$. Neste sistema, o $\mathrm{H}_{2}$ produzido dentro do erlenmeyer percorreria a mangueira até chegar ao interior da proveta, preenchida com água, e a pressão exercida pelo gás produzido faz com que a água se desloque abaixando o nível de água de dentro da proveta, sendo, desta forma, possível fazer a leitura da quantidade de gás produzido pelo volume do espaço isento de água lido na proveta graduada. O gás produzido foi coletado para posterior análise no cromatógrafo gasoso. Foram feitos três planejamentos, no software Statistica ${ }^{\circledR}$, considerando-se três níveis em que as variáveis independentes foram massas de três tipos metais residuais com fonte de ferro (vergalhão (resíduo de construções), pó de ferro ( resíduo de serralherias/ tornearias) e palha de aço), fração volumétrica $\left(\mathrm{H}_{2} \mathrm{SiF}_{6} / \mathrm{HCl}\right)$ e tempo e a variável dependente foi o volume de gás produzido.

Figura 1: Representação esquemática da montagem experimental,

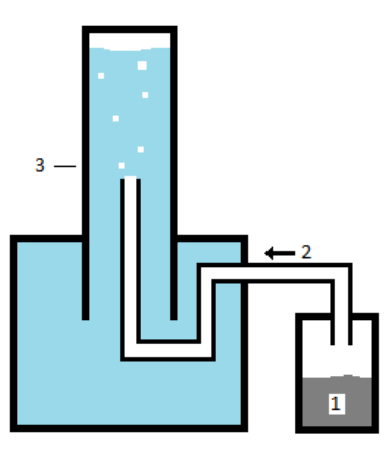

Onde:

1. Reator para o processo de corrosão;

2. Liberação de gás e seu fluxo;

3. Recipiente para coleta do gás

liberado.

Através da análise das superfícies de resposta obtidas e parâmetros significativos, foi realizado um Planejamento Composto Central (PCC), obtendo-se assim a otimização do sistema.

\section{RESULTADOS}

Para os experimentos realizados com vergalhão, após o PCC, encontrou-se um valor de $\mathrm{R}^{2}$ de 0,828 . Verificou-se que o tempo linear é mais significativo. Massa quadrática, massa linear, fração linear e a interação entre a fração linear e o tempo linear também são significativos. Observou-se também que os pontos analisados seguem o modelo e que esse não apresentou nenhuma tendência, sendo assim apropriado para a análise. Por meio das superfícies de resposta, não foi possível encontrar um ponto de ótimo, sendo encontrado um ponto de cela, como verificado na Figura 2. Como a fração deve ser menor que 1 e há limitações físicas para o sistema, os valores máximo e mínimo encontrados, bem como valor crítico, encontram-se na Tabela 1.

Já nos experimentos realizados com o pó de ferro, utilizando o PCC, a massa foi mantida constante e o valor do $\mathrm{R}^{2}$ foi de 0,983 , sendo a fração linear a mais significativa. Foi possível notar que os dados se ajustaram ao modelo. Ao se analisar a superfície de resposta da fração com o tempo Figura 3, verificou-se que o aumento dessas variáveis apresenta uma influência positiva na resposta. Era esperado que o valor crítico dado fornecido fosse o ponto 
ótimo do processo, no entanto, o valor crítico apresentado é um ponto de cela e não o ponto de maior produção. Assim, devido as limitações físicas do experimento, obteve-se a Tabela 2, com os pontos de máximo observado e mínimo observado e o ponto crítico calculado pelo software.

Com os experimentos realizados com a palha de aço, após o PCC, manteve-se o tempo constante em 10 minutos. Encontrou-se um valor de $\mathrm{R}^{2}$ de 0,960 , sendo a massa linear a mais significativa, seguido pela fração linear. A interação de massa com fração, ou até mesmo o fator quadrado não apresentou significância. Obteve-se um bom ajuste para valores preditos vs. valores observados e o modelo pôde ser considerado apropriado pois o gráfico de resíduos não apresentou nenhuma tendência. Pela superfície de resposta (Figura 4) observa-se que o aumento das variáveis massa e fração causam uma resposta positiva no sistema. Devido às limitações físicas do sistema, o ponto ótimo será o ponto de máximo observado com massa de $2,105 \mathrm{~g}$ e fração volumétrica de 0,9 ; sendo os pontos de máximo e mínimo observados dispostos na Tabela 3 .

Tabela 1- Ponto crítico obtido pelo programa Statistica ${ }^{\circledR}$ e os valores máximo e mínimos encontrados para o vergalhão

\begin{tabular}{|c|c|c|c|}
\hline Fator & Mínimo observado & Valor crítico & $\begin{array}{c}\text { Máximo } \\
\text { observado }\end{array}$ \\
\hline Fração & $1,96 \times 10^{-1}$ & $3,76 \times 10^{-1}$ & $9,03 \times 10^{-1}$ \\
\hline Massa & $5,50 \times 10^{0}$ & $4,10 \times 10^{1}$ & $1,04 \times 10^{2}$ \\
\hline Tempo & $1,17 \times 10^{1}$ & $2,52 \times 10^{1}$ & $6,83 \times 10^{1}$ \\
\hline
\end{tabular}

Tabela 2- Ponto crítico obtido pelo programa Statistica ${ }^{\circledR}$ e os valores máximo e mínimos encontrados para o pó de ferro

\begin{tabular}{|c|c|c|c|}
\hline Fator & Mínimo observado & Valor Crítico & Máximo Observado \\
\hline Tempo & $7,40 \times 10^{-1}$ & $8,03 \times 10^{0}$ & $1,53 \times 10^{1}$ \\
\hline Fração & $2,30 \times 10^{-1}$ & $2,80 \times 10^{-1}$ & $9,60 \times 10^{-1}$ \\
\hline
\end{tabular}

Tabela 3 - Ponto crítico obtido pelo programa Statistica ${ }^{\circledR}$ e os valores máximo e mínimos encontrados para a palha de aço

\begin{tabular}{|c|c|c|}
\hline Fator & Mínimo observado & Valor crítico \\
\hline Massa & $8,95 \times 10^{-1}$ & $2,10 \times 10^{0}$ \\
\hline Fração & $4,58 \times 10^{-1}$ & $9,42 \times 10^{-1}$ \\
\hline
\end{tabular}

Os resultados encontrados, como pode ser observado por meio das superfícies de respostas, analisando-se o volume obtido no ponto de máximo para cada material, indicam que a produção de $\mathrm{H}_{2}$ foi maior para o pó de ferro, em seguida para a palha de aço e o que apresentou menor produção foi o vergalhão. Para todos os materiais, o aumento das variáveis, tempo, massa e fração causa um efeito positivo para a produção de $\mathrm{H}_{2}$, sendo que as limitações físicas do sistema considerado, como a fração de ácido e a capacidade da proveta utilizada para medir o volume de gás produzido, foi o que impediu uma maior produção. 


\section{C $\$$ BEO 200

Realizou- se a análise por cromatografia gasosa do gás produzido e como resultado, para todos esses materiais, descobriu-se que havia nas amostras coletadas, apenas $\mathrm{H}_{2} \mathrm{e}$ ar.

Figura 2- Superfície de resposta do efeito de massa de ferro e tempo de reação para ensaios com vergalhão após o PCC.

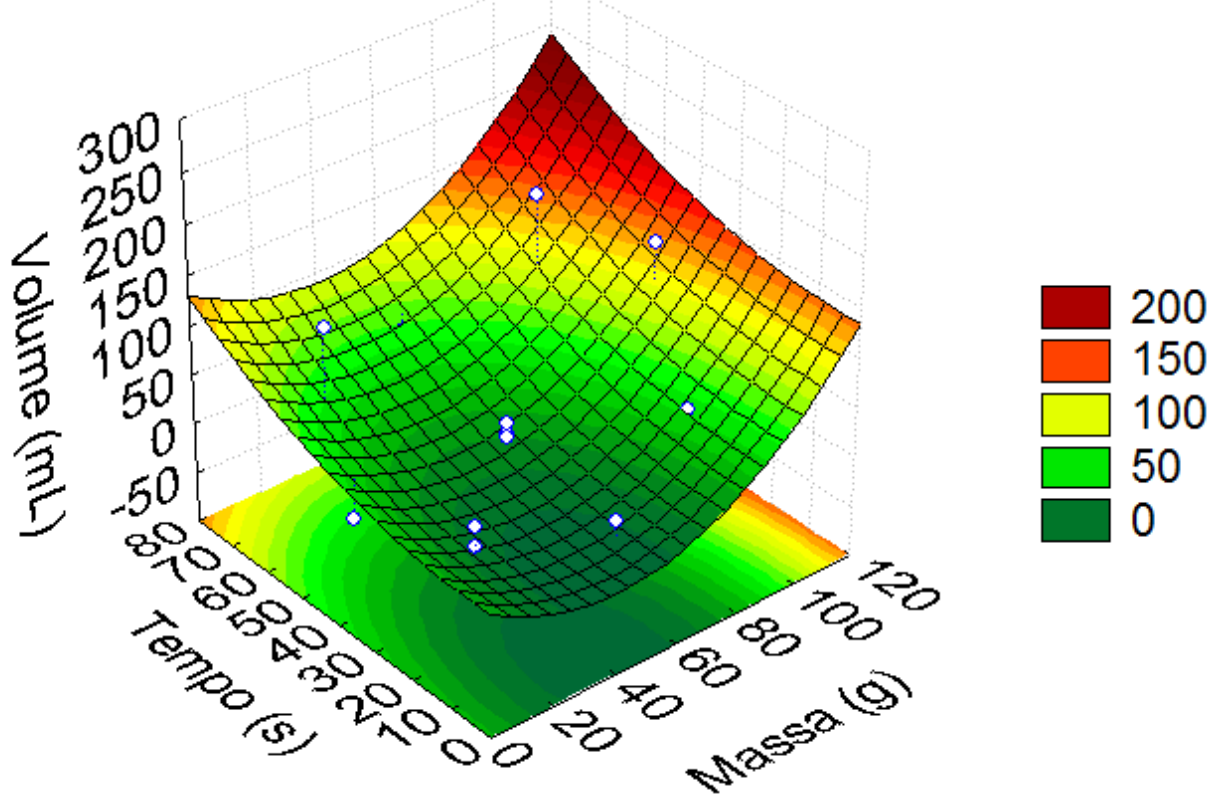

Figura 3 - Superfície de resposta para experimentos com o pó de ferro após o PCC.

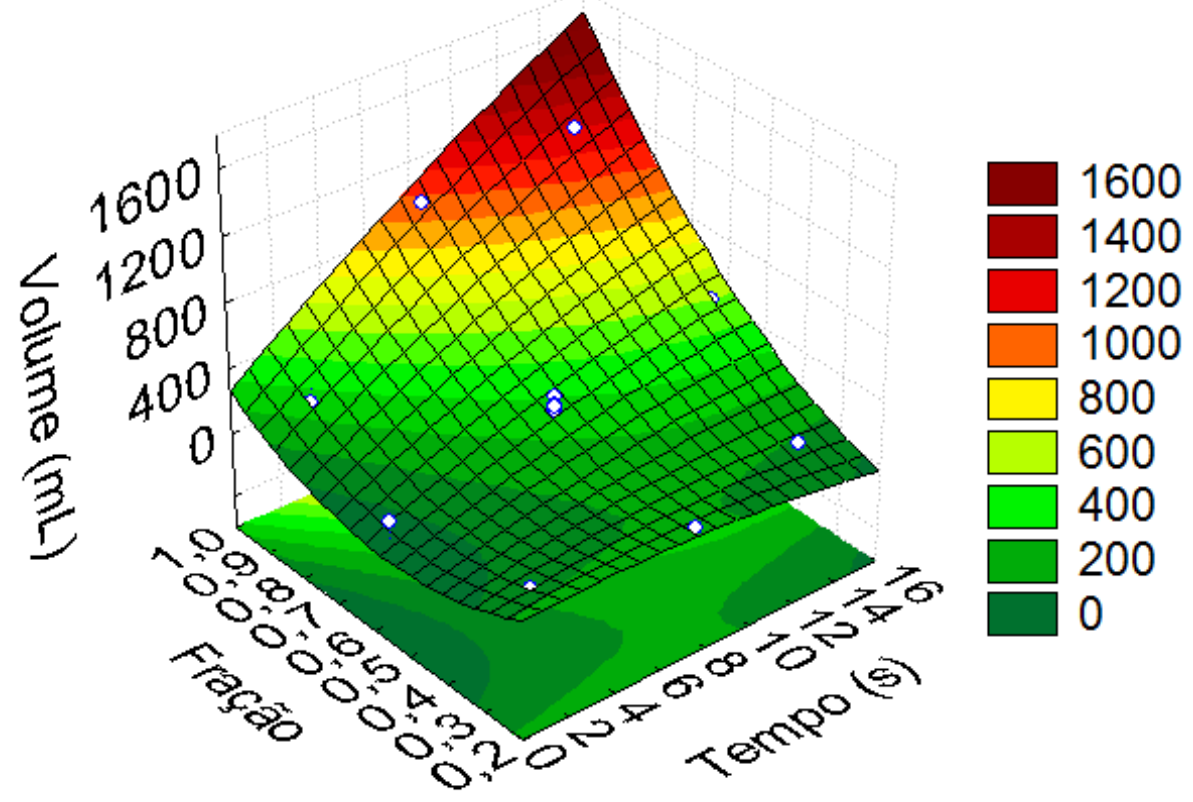


Figura 4- Superfície de resposta para experimentos com a palha de aço após o PCC.

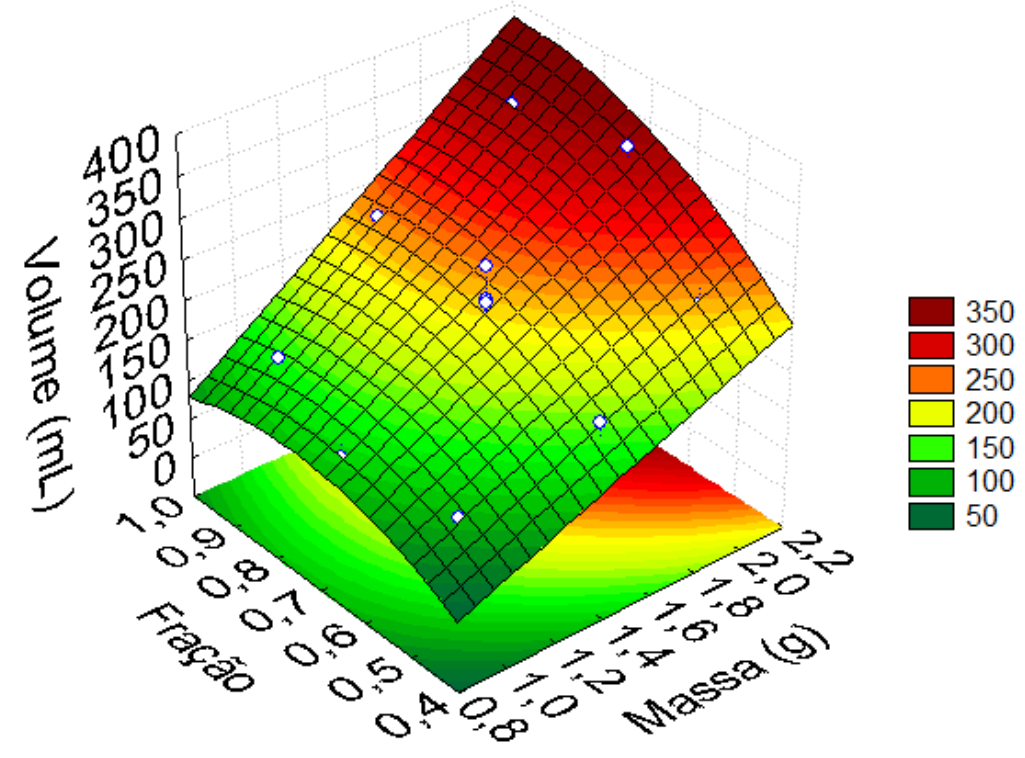

Sendo assim, é possível gerar-se $\mathrm{H}_{2}$ reaproveitando-se pó de ferro, vergalhão e palha de aço. Porém, para se ter uma produção maior, o pó de ferro é melhor, devido a sua maior superfície de contato, assim como o vergalhão apresentou uma menor produção, por causa da menor superfície de contato e da dificuldade maior de ocorrer a corrosão devido a uma possível formação de óxido que funciona como película protetora na superfície do metal.

\section{CONCLUSÃO}

Pode-se concluir que a geração de hidrogênio por meio da corrosão ácida utilizando $\mathrm{H}_{2} \mathrm{SiF}_{6}$ e metais residuais mostrou ser um método eficiente, que não emite nenhum gás tóxico ou poluente e não envolve grandes gastos econômicos, contribuindo assim para geração de hidrogênio, uma nova fonte de energia obtida de maneira sustentável.

\section{AGRADECIMENTOS}

FAPEMIG e CNPq.

\section{REFERÊNCIAS}

GENTIL, Vicente. Corrosão. Rio de Janeiro: LTC, 2014, $9^{a}$ ed.

LEE, J. D.. Química inorgânica não tão concisa. 5 ed, São Paulo: Blucher, 1999

YU, Shih-hao; UAN, Jun- Yen; HSU, Tsang- Lin. Effects of concentrations of $\mathrm{NaCl}$ and organic acid on generation of hydrogen from magnesium metal scrap. International Journal Of Hydrogen Energy. [s.i.], p. 3033-3040. fev. 2012. Disponível em: $<$ http://www.sciencedirect.com/science/article/pii/S0360319911025389>. Acesso em: 09 maio 2017.

LIANG, J. et al. Hydrogen generation by reaction of Al-M (M= Fe,Co,Ni) with water. Energy. [s.i.], p. 282-287. jul. 2016. 